\title{
Comment on Myocardial Perfusion Study in Obese Patients without Known Cardiac Ischemia
}

\author{
Claudio Tinoco Mesquita ${ }^{1,2}$ and Gustavo Gavina da Cruz ${ }^{3,4}$ \\ Universidade Federal Fluminense - Departamento de Radiologia, ${ }^{1}$ Niterói, RJ - Brazil \\ Hospital Pró-cardíaco, ${ }^{2}$ Rio de Janeiro, RJ - Brazil \\ Universidade Federal Fluminense - Pós-Graduação em Ciências Cardiovasculares, ${ }^{3}$ Niterói, RJ - Brazil \\ Fundação Técnico Educacional Souza Marques, ${ }^{4}$ Rio de Janeiro, RJ - Brazil
}

"All human knowledge is fallible and therefore uncertain.

It follows that we must distinguish sharply between truth and certainty... This is the task of scientific activity. Hence, we can say: our aim as scientists is objective truth; more truth, more interesting truth, more intelligible truth.

We cannot reasonably aim at certainty."

Karl Popper

We congratulate Dippe et al. ${ }^{1}$ for their work that addressed the role of myocardial scintigraphy in the diagnosis of myocardial ischemia in obese patients. ${ }^{1}$ Despite limitations, body mass index (BMI) has been the most used anthropometric tool for assessing nutritional status in adults. ${ }^{2}$ Epidemiologic studies have identified high $\mathrm{BMI}$ as a risk factor for an expanding set of chronic diseases, including cardiovascular disease and diabetes mellitus. The Global Burden of Disease (GBD) Obesity Collaborators found that excess body weight accounted for about 4 million deaths in 2015 . Nearly $70 \%$ of these deaths were due to cardiovascular disease, and more than $60 \%$ of them occurred among obese persons $\left(\mathrm{BMI} \geq 30 \mathrm{Kg} / \mathrm{m}^{2}\right){ }^{3}$ The use of a database of consecutive patients provides a sample of obese patients from the real-world scenario and portrays the current clinical practice in which the cardiologist faces major diagnostic challenges in obese patients. All diagnostic methods have significant challenges in obese patients such as the limitation of the acoustic window in the echocardiogram, higher incidence of photon attenuation on computed tomography and myocardial scintigraphy and bore size limitations to cardiac resonance imaging. Radiation-sparing techniques are more difficult to use in heavier patients. ${ }^{4}$ The finding that clinical data such

\section{Keywords}

Coronary Artery Disease; Myocardial Perfusion Imaging; Obesity/mortality; Myocardial Ischemia; Diabetes Mellitus.

\section{Mailing Address: Claudio Tinoco Mesquita •}

Universidade Federal Fluminense Faculdade de Medicina - Departamento de Radiologia - Av. Marques do Paraná, 303. CEP 24230-322, Centro, Niterói, RJ - Brazil

E-mail: claudiotinocomesquita@gmail.com

Manuscript received February 19, 2019, revised manuscript March 27, 2019, accepted March 27, 2019 as the presence of diabetes mellitus, older age and typical symptoms of angina highlights the need of careful clinical evaluation in order to adequate request ischemic screening tests in patients with suspected coronary artery disease, especially in the obese. Another important finding of their study was the absence of association between obesity alone, especially in the group with BMI greater than 40, with the presence of ischemia. A technical aspect that was not clear in the article and whether the authors used the prone acquisition when there was doubt about the presence of breast attenuation and also the technique used to quantify the visual or automatic ischemia.

In an editorial about this article, Hueb ${ }^{5}$ points out the multiple mechanisms involved in the pathophysiology of myocardial ischemia, including the microvascular mechanisms that determine ischemia in patients with epicardial coronary arteries without obstruction. Functional methods are important in the identification of microvascular ischemic abnormalities, which have diagnostic and prognostic value, especially in diabetic patients and in patients with multiple risk factors. Functional imaging is superior to anatomic imaging in patients with microvascular disease because of their focus on different levels of the ischemic cascade including wall motion abnormalities (echocardiography and stress cardiac magnetic resonance), relative perfusion abnormalities (stress cardiac magnetic resonance and single-photon emission computed tomography), and changes in physiological absolute regional myocardial perfusion (PET). ${ }^{6}$ The creation of the patient-centered imaging culture that prioritizes patient safety and effectiveness requires the understanding of the better diagnostic techniques for every clinical need. ${ }^{7}$

Karl Popper stated that science is composed of transient truths. The role of scientists is to prove the falsifiability of their findings and others in the search of a more intelligible true. In the absence of contrary evidence, current evidence points that invasive treatment in patients with myocardial ischemia area greater than $10 \%$ is associated with better prognosis in comparison with medical management alone. The results of the ISCHEMIA study to be published in the near future should provide additional new scientific evidence regarding whether an invasive management strategy improves clinical outcomes when added to optimal medical therapy in patients moderate or severe ischemia. ${ }^{8}$

DOI: $10.5935 / a b c .20190082$ 


\section{References}

1. Dippe Jr T, Leinig C, Cerci RJ, Lafitte A, Stier Jr AL, Vítola JV. Study of myocardial perfusion in obese individuals without known ischemic heart disease. Arq Bras Cardiol. 2019;112(2):121-8.

2. Bastien M, Poirier P, Lemieux I, Després J. Overview of epidemiology and contribution of obesity to Cardiovascular disease. Prog Cardiovasc Dis. 2014;56(4):369-81.

3. Afshin A, Forouzanfar MH, Reitsma MB, Sur P, Estep K, Lee A, et al; The GBD 2015 Obesity Collaborators. Health effects of overweight and obesity in 195 countries over 25 years. N Engl J Med. 2017;377(1):13-27.

4. Lim SP, Arasaratnam P, Uk M, Chow BJ, Beanlands RS. Obesity and the challenges of noninvasive imaging for the detection of coronary artery disease. Can J Cardiol. 2015;31(2):223-6.
5. HuebW. Single photon computed tomography-myocardial perfusion scintigraphy. Diagnostic tool anticipating the disease. Arq Bras Cardiol 2019;112(2):129.

6. Knuuti J, Ballo H, Juarez-orozco LE. The performance of non-invasive tests to rule-in and rule-out significant coronary artery stenosis in patients with stable angina: a meta-analysis focused on post-test disease probability. Eur Heart J. 2018;39(35):3322-30.

7. Einstein AJ, Berman DS, Min JK, Hendel RC, Gerber TC, Carr JJ, et al. Patientcentered imaging: shared decision making for cardiac imaging procedures with exposure to ionizing radiation. J Am Coll Cardiol. 2014;63(15):1480-9.

8. Maron DJ, Hochman JS, Brien SMO, O'Brien SM, Reynolds HR, Boden WE, et al. International Study of Comparative Health Effectiveness with Medical and Invasive Approaches (ISCHEMIA) Trial: Rationale and Design. Am Heart J. 2018 July;201(124):124-35.

includes patients referred to our diagnostic center, about whom we have no control over which are the tests to be recommended, as this is the responsibility of the referring clinician. (I do not understand this)

Besides that, we cannot infer that the tests have been inappropriately recommended based on $77 \%$ of normal scintigraphies. We are sure that this data should not be used as a criticism of our study, since in many clinical situations this is exactly the information sought by the clinician requesting a provocative ischemia test, that is, the absence of ischemia can avoid unnecessary anatomical evaluations, such as cineangiocorography, for example.

It is true that many of these patients with suspected CAD could have their disease ruled out by coronary angiography. Unfortunately, this practice is still limited in our country, because of the restrictions imposed by health insurance plans or unavailability in the public health system (SUS). We believe that this would be an excellent way to "rule out" CAD, avoiding additional tests, including myocardial perfusion scintigraphy itself.

Although our perfusion abnormality rate $(23 \%)$ was considered low by Dr. Whady Hueb, it is nearly three times greater than that found in reference laboratories in the United States, as found by the Cedars Sinai Hospital registry, which revealed about $8.7 \%$ of perfusion abnormalities. ${ }^{11}$ Similarly, the randomized study PROMISE $^{12}$ found a perfusion abnormality rate close to $10 \%$ in symptomatic patients.

In our sample, $31 \%$ of the patients were known diabetics, and this certainly differentiates our group from other studies, and helps us understand our high abnormality rate.

Another excerpt of the short editorial reads: based on this data, by applying a "creative statistics", they found a 245\% risk increase for typical angina.

Note that nowhere in the manuscript we mentioned that a perfusional abnormality would increase the risk of typical angina. We have published that the patients who reported typical angina before the test, compared to asymptomatic patients (reference) had 245\% higher chances of having

Note that our registry in Curitiba, which is certainly one of the largest nuclear cardiology registries in the world, 


\section{Letter to the Editor}

abnormal myocardial perfusion (odds ratio of 2.45 [1.82-3.31], see page 125 of the manuscript, table 4). ${ }^{1}$ There is no "creative statistics" at all. This conclusion was reached after multivariate logistic regression analysis. It is pure statistics.

Finally, we would like to thank UFF for the letter sent to the editor of Arquivos Brasileiros de Cardiologia and to
Dr. Whady Hueb for his short editorial. The productive discussion and scientific production certainly help to add further value to our admired Brazilian cardiology.

Tufi Dippe Junior João Vicente Vítola

\section{References}

1. Dippe Jr T, Leinig C, Cerci RJ, Lafitte AS Jr, Vítola JV. Estudo de perfusão miocárdica em obesos sem doença cardíaca isquêmica conhecida. Arq Bras Cardiol. 2019;112(2):121-8.

2. Hueb W. A cintilografia de perfusão miocárdica com tomografia computadorizada por fóton unico. Ferramenta diagnóstica antecipando a doença. Arq Bras Cardiol 2019;112(2): 129.

3. Gallagher D, Heymsfield SB, Heo M, JebbSA, Murgatroyd PR, Sakamoto Y. Healthy percentage body fat ranges: an approach for Developing guidelines based on body mass index. Am J Clin Nutr. 2000;72 (3): 694-701.

4. Shiwaku K, Kitajima K, Yamane Y. Appropriate BMI for Asian populations. Lancet. $2004 ; 363$ (9414): 1077.

5. Deurenberg P, Yap M, Wang J, Lin FP, Schmidt G. The impact of body build on the relationship between body mass index and percent body fat. Int J Obes Relat Metab Disord. 1999;23(5):537-42.

6. Hubert HB, Feinleib M, McNamara PM, Castelli WP. The obesity an independent risk factor for cardiovascular disease: a 26-year follow-up of participants in the Framingham Heart Study. Circulation. 1983;67(5):968-77.

7. Manson JE, Colditz GA, Stampfer MJ, WillettWC, Rosner B, Monson RR,et al. A prospective study of obesity and risk of coronary heart disease in women. N Engl J Med 1990;322(13):882-9.

8. World Health Organization. (WHO). Obesity: Preventing and managing the global epidemic. Report of the World Health Organization Consultation. Geneva; 2000. ( WHO Obesity Technical Report Series, No. 284)

9. Hueb W, Bellotti G, de Oliveira SA, Ariê S, Albuquerque CP, Jatene AD, Pileggi F. The Medicine, Angioplasty or Surgery Study (MASS): a prospective, randomized trial of medical therapy, balloon angioplasty or bypass surgery for single proximal left anterior descending artery stenoses. J Am Coll Cardiol. 1995;26(7):1600-5.

10. Hochman JS, Harmony RS, Bangalore S, O'Brien SM, Alexander $K P$, Senior R, et al. Baseline Characteristics and risk profiles of participants in the ISCHEMIA Randomized Clinical Trial. JAMA Cardiol. 2019;4(3):273-86.

11. Rozanski A, Gransar H, Hayes SW, Min J, Friedman JD, Thomson LF, et al. Temporal trends in the frequency of inducible myocardial ischemia during cardiac stress testing: 1991 to 2009. J Am Coll Cardiol. 2013;61(10):1054-65.

12. Douglas PS, Hoffmann U, Patel MR, Mank DB, Al-Khalidi HR, Cavanaugh $B$, et al. for the PROMISE Investigators. Outcomes of anatomical versus functional testing for coronary artery disease. $\mathrm{N}$ Engl J Med. 2015;372(14):1291-300. 